\title{
Major predictors of growth hormone and cardiovascular risk: systematic review and meta- analysis
}

\begin{abstract}
Significance: About 17.5million people die each year from cardiovascular disease (CVD). In Brazil, CVDs are leading causes of death. They represent $29.0 \%$ of the deaths and, in January 2017, they were responsible for more than 30 thousand deaths. In 2016, the Brazilian Society of Cardiology recorded 349,938 deaths. An estimated 6,000 adults are diagnosed with growth Hormone deficiency (AGHD) every year in the United States, whereas its incidence is approximately 2 cases per 100,000 population when childhood-onsetGH deficiency patients are considered. Growth hormone $(\mathrm{GH})$ may reduce cardiovascular risks.
\end{abstract}

Information gaps: There is a lack of available scientific data on cardiac changes and cardiovascular risks observed in growth hormone deficiency (GHD).

Objective: A meta-analysis was performed to evaluate clinical evidence on the effects of GH replacement therapy on cardiovascular risk

Methods: Followed the PRISMA guidelines. The descriptors IGF-1, GH/IGF-1, growth hormone, coronary diseases, cardiovascular risk were used.

Results: Patients with GHD had a reduced aortic area and, after 1year of GH replacement, increased left ventricular mass index, increased non-fat mass and LDL reduction

Conclusion: GH deficiency is a major risk factor that causes various reactions in the body, leading to heart disease.

Keywords: IGF-1, GH/IGF-1, growth hormone, coronary diseases, GH decrease, risk factors for coronary disease
Volume 6 Issue 4 - 2018

\author{
Ana Valéria Garcia Ramirez, ${ }^{1,2}$ Durval Ribas \\ Filho,' Larissa Bianca Paiva Cunha de Sá, \\ Alberto K Arbex ${ }^{2}$ \\ 'Brazilian Association of Nutrology, Brazil \\ ${ }^{2}$ Institute for Research and Medical Education, Brazil
}

Correspondence: Ana Valéria Garcia Ramirez, Brazilian Association of Nutrology, Catanduva, Rua Belo Horizonte, 976Centro-Catanduva, São Paulo, SP, Brazil, Zip code 1580I-150, Email anaramirez@terra.com.br

Received: May 23, 2018 | Published: July 30, 2018

\section{Introduction}

Cardiovascular diseases (CVD) are the leading causes of death in the population. According to World Health Organization data from 2016, of the 20.8million deaths from these diseases, 9.2million occur due to coronary artery disease (CAD) ${ }^{1,2}$ An estimated 6,000 adults are diagnosed with growth Hormone deficiency (AGHD) every year in the United States. AGHD has been estimated to affect 1 in 100,000 people annually, whereas its incidence is approximately 2 cases per 100,000 population when childhood-onsetGH deficiency patients are considered. ${ }^{3}$ Some of the risk factors for atherosclerosis are currently well known, such as hypercholesterolemia, hypertension, smoking, diabetes mellitus, family history and sedentary lifestyle on a smaller scale. In recent years, research on atherosclerotic disease has focused mainly on changes in the lipid profile, since large studies have shown a correlation between dyslipidemia and coronary artery disease. ${ }^{4,5}$

The Framingham study, conducted with about 5,000 residents of this community in Massachusetts, showed a increased risk of higher levels of LDL cholesterol and lower HDL. Once this correlation has been demonstrated, several studies have succeeded, confirming the hypothesis that it is possible to control cardiovascular events by normalizing cholesterol levels. ${ }^{6}$ However, many patients with cardiovascular disease have normal cholesterol levels. It is estimated that they represent $30-35 \%$ of patients with CAD. Therefore, there is a search for new factors that may be involved in the genesis of coronary artery disease. ${ }^{6,7}$ There are a number of risk factors for cardiovascular disease, highlighted and described in the scientific literature. In particular, growth hormone $(\mathrm{GH})$ has multiple roles in supporting human development and homeostasis. ${ }^{8}$ Its pulsatile secretion stimulates growth and contributes to a balance in a wellregulated and coordinated process by many organs. ${ }^{6}$ Between 18 and $25 y e a r s$ there is an exponential decrease in the mean GH secretion, with drop in IGF-1 levels. ${ }^{6,8}$ By age 60 , many people may experience a low rate of daily $\mathrm{GH}$ secretion. ${ }^{6}$ Its release in the body occurs mainly at night, in pulses, in the first hours of sleep, so it is not difficult to understand why a well-slept night would release a discharge of GH in the body. Another situation that stimulates the release of this hormone is the practice of physical activity, especially anaerobic, in which the release of lactic acid stimulates the release of this hormone, as well as testosterone.

GHD is a important frequency medical condition that can affect all ages, with significant consequences on the patient's health, including quality of life. However, the physiological decline of GH with age is not seen as an illness. This review brings together the different strategies used today with a look at future technologies to treat GHD. We present fundamental aspects for consideration when developing new methods to deliver $\mathrm{GH}$, mimicking or replacing its pulsatile activity. ${ }^{9,10}$ The main information gap in the present study was the 
still scarce literature, the interpretation of the GH decrease, as a risk factor for coronary diseases, the great bibliographic survey study, justifies our objectives. Thus, the present study aimed to describe the decrease in GH levels and its influence in patients with cardiovascular complications, which implies a risk factor for coronary diseases.

\section{Methods}

\section{Study design}

Following the criteria of literary search with the use of the MeSHterms that were mentioned in the item below in "Searchstrategy". A total of 82 papers that were submitted to the eligibility analysis were collected and, after that, 37 studies were selected, following the rules of the systematic review-Transparent Reporting of Systematic Reviews and Meta-analyses (PRISMA-http: //www.prisma-statement.org/).

\section{Eligibility criteria and selection of studies}

The inclusion criteria were as follows: none of the patients had received GH therapy and all patients received adequate replacement therapy from the other pituitary hormones. In all patients, the levels of all hormones, except GH, were kept within the normal reference range. The exclusion criteria for both groups were as follows: (1) current treatments with drugs that interfere with glucose metabolism, lipid metabolism or blood pressure; (2) presence of previous diagnosis of diabetes mellitus, hypertension or malignant tumor; (3) current treatment with GH; (4) functional disorders of the liver and kidney or mental disorder.

\section{Sources of information}

The review protocol was based on literary search criteria with the use of MeSH terms in the main databases such as PubMed, MEDLINE, Bireme, EBSCO, Sci ELO, etc. All references are recorded in End Note on the website http://www.myendnoteweb.com/EndNoteWeb. html? cat=myrefs \&.

\section{Search strategy}

In general, as an example, the research strategy in MEDLINE/ PubMed, Web of Science, Science Direct Journals (Elsevier), Scopus (Elsevier), OneFile (Gale) followed the following steps: (1) search for MeSHterms (coronary disease, IGF-1, GH/IGF-1, growth hormone, coronary diseases, GH decrease, GH index,risk factors for coronary heart disease, diabetes, obesity, hypertension, dyslipidemia and clinical trials);(2) use of the Boolean operators "and" between the terms and "or" between historical findings.

\section{Statistical treatment of literary findings}

Statistical analysis of the data was performed and interpreted by the author of the present study. For data analysis, a database was created in the Microsoft Excel spreadsheet that was exported to the Minitab 17 statistical program. A common descriptive statistical analysis and Anderson-Darling normality test were performed for all variables and controls with reference $p>0.10$ as "normal". As there were continuous and categorical predictors (GH deficiency parameters - test group) and predictors of response (parameters in the normal GH control group), linear regression and residual Durbin-Watson analysis were applied. For all linear regression tests, the alpha level of less than 0.05 was adopted as significant. For the Durbin-Watson residue analysis, the significance level of reference was 0.05 , adopting as acceptable independence tolerance $0.95<\mathrm{dw}<1.54$ (according to the
Durbin-Watson standard table, $\mathrm{dU}<\mathrm{dw}<4-\mathrm{dU}$ ), with two explanatory variables for the sample size of $n=30$.

\section{Results and statistical approach}

According to Table 1, the main parameters found in the literature on cardiovascular risk assessment in relation to GHD were summarized quantitatively. The parameters found were gender, age, current drinker, current smoker, exercise, BMI (body mass index), waist circumference, hip circumference, WHR (waist-hip ratio), SBP (systolic blood pressure) diastolic blood pressure, fasting glycemia, HOMA-IR (homeostasis model assessment of insulin resistance), TC (total cholesterol), TG (triglycerides), HDL and LDL. After regression analysis between continuous predictors (GH deficiency parameters - test group) and response (parameters in the normal GH control group), all analyses presented statistical difference $(p>0.05)$, except waist circumference, WHR, SBP, fasting glycemia, TG and HDL, with $p<0.05$, that is, these last analyses showed similarities in dosed amounts, indicating that GH did not affect these measures. These findings confirm the $\mathrm{p}$ values shown in the previous paragraph.

Table I Main parameters and predictors of the relationship between $\mathrm{GH}$ and cardiovascular risk

\begin{tabular}{|c|c|c|c|}
\hline & GHD & Control & p-value \\
\hline Gender & $40 / 51$ & $71 / 69$ & $\mathrm{p}=0.254$ \\
\hline Age & $46.86 \pm 15.95$ & $44.96 \pm 13.42$ & $\mathrm{p}=0.467$ \\
\hline $\begin{array}{l}\text { Current } \\
\text { drinker,n(\%) }\end{array}$ & $70(76.1 \%)$ & $55(23 \%)$ & $\mathrm{P}=0.734$ \\
\hline $\begin{array}{l}\text { Current } \\
\text { smoker,n(\%) }\end{array}$ & $21(19.5 \%)$ & $24(11.5 \%)$ & $\mathrm{p}=0.247$ \\
\hline Exercise, n(\%) & $14(15.4 \%)$ & $32(22.9)$ & $\mathrm{p}=0.342$ \\
\hline $\mathrm{BMI}, \mathrm{kg} \mathrm{cm}{ }^{2}$ & $24.22 \pm 4.08$ & $23.95 \pm 2.92$ & $\mathrm{p}=0.487$ \\
\hline $\begin{array}{l}\text { Waist } \\
\text { circumference, cm }\end{array}$ & $84(76-90)$ & $82(73-86)$ & $\mathrm{P}=0.00 \mathrm{I}$ \\
\hline $\begin{array}{l}\text { Hip } \\
\text { circumference, } \mathrm{cm}\end{array}$ & $95(89-99)$ & $93(91-97)$ & $\mathrm{P}=0.568$ \\
\hline WHR & $0.90 \pm 0.63$ & $0.84 \pm 0.09$ & $\mathrm{p}<0.00 \mathrm{I}$ \\
\hline $\mathrm{SBP}, \mathrm{mmHg}$ & $120(106.5-130)$ & $122(1 \mid 2.25-134)$ & $\mathrm{p}=0.045$ \\
\hline DBP, mmHg & $73(65-82)$ & $76(67-82$ & $\mathrm{p}=0.523$ \\
\hline $\begin{array}{l}\text { Fasting blood } \\
\text { glucose, } \mathrm{mmol} / / \mathrm{l}\end{array}$ & $5.2(5.03-5.8)$ & $4.8(4.6-5.6)$ & $\mathrm{p}=0.003$ \\
\hline HOMA-IR & $0.99(0-2.52)$ & $\mathrm{I} .40(0.8-2.0 \mathrm{I})$ & $\mathrm{p}=0.083$ \\
\hline $\mathrm{TC}, \mathrm{mmol} / \mathrm{l}$ & $4.50(3.77-5.64)$ & $4.60(4.1 \mathrm{I}-5.42)$ & $\mathrm{p}=0.639$ \\
\hline $\mathrm{TG}, \mathrm{mmol} / \mathrm{l}$ & $1.52(0.92-2.6)$ & I.0I(0.79-I.79) & $\mathrm{p}=0.002$ \\
\hline $\mathrm{HDL}, \mathrm{mmol} / \mathrm{l}$ & I.02(0.87-I.54) & $1.55(1.25-1.73)$ & $\mathrm{p}<0.00 \mathrm{I}$ \\
\hline LDL, mmol/l & $2.80 \pm 1.25$ & $2.50 \pm 0.88$ & $p=0.735$ \\
\hline
\end{tabular}

In addition, to further deepen the statistical correlation between the parameters, a residual Durbin-Watson analysis was performed. This analysis revealed that, in fact, there was no relation of dependence (significance) between the analysed data. Thus, the results were confirmed by Figure 1, where the residues appeared to follow a straight line. There was no evidence of discrepant or unidentified variables; the waste appears to be randomly scattered around zero. There was 
no evidence of non-constant variance, absent terms, discrepant points or influential points; the histogram did not follow a normal curve; the residues appeared to be randomly scattered around zero. There was no evidence that the error correlates with one another.
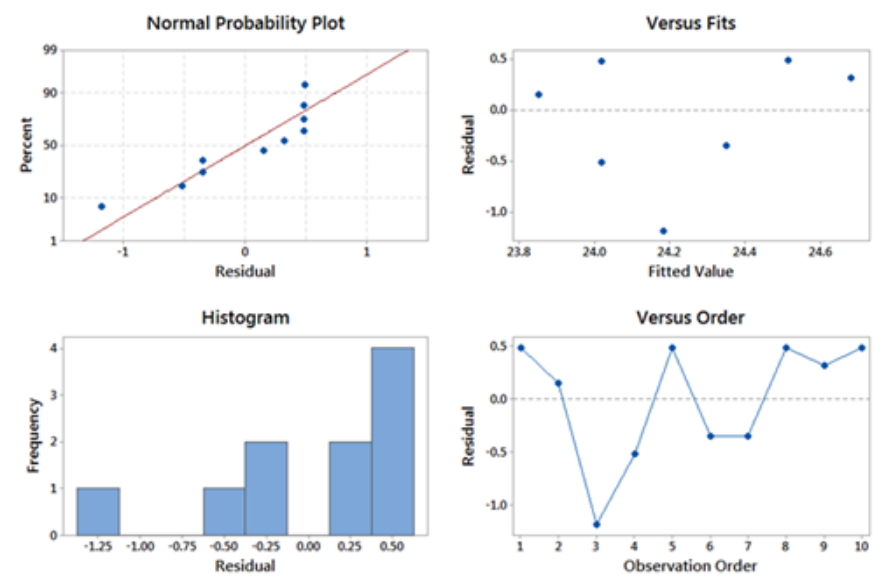

Figure I Representative durbin-watson residual analysis among the predictors of Table I.

\section{Development-literary review}

Growth hormone is the most abundant in the anterior pituitary, synthesized and secreted by somato trophs, $50.0 \%$ of pituitary hormone-secreting cells. ${ }^{11-15}$ Based on studies of heterogeneous groups of patients with GHD, increased cardiovascular mortality was associated with this disorder in adults, ${ }^{16,17}$ due to several factors, such as: atherosclerotic changes, abdominal adiposity, dyslipidemias (cholesterol) and elevation of high-sensitivity C-reactive protein (hsCRP). ${ }^{18}$ Patients with isolated GHD reduced insulin-like growth factor 1 (IGF-1) have an adverse cardiovascular profile, including obesity, small amounts of lean mass, increased fat percentage, increased systolic blood pressure, and high level of hsCRP, in addition to total cholesterol and LDL increase. ${ }^{3,13,19}$

In this context, a meta-analysis aimed to assess whether existing clinical evidence can determine the effects of growth hormone replacement therapy on cardiovascular risk, both in GH deficiency alone and in compensated hypopituitarism, including GH deficiency. ${ }^{20}$ Increased fat-free mass and fat mass (FM) reduction were found, along with a reduction in LDL-C, a large variation in glycemia and a neutral effect on glycated hemoglobin (HbAlc) and blood pressure. These effects were valid for both patients with GHD. The overall score showed a non-significant reduction in overall cardiovascular risk $(0.53 ; 95.0 \% \mathrm{CI}:-1.23,2.85) .{ }^{20}$ Meta-analysis did not show a significantly positive trend in cardiovascular risk following short- and long-term GH supplementation therapy in adult patients with GHD. However, a reduction in LDL cholesterol levels was found. ${ }^{21}$

Many previous studies have observed that current consumption of tobacco and alcohol is associated with cardiometabolic risk and mortality. ${ }^{22}$ However, there was no significant difference between GHD and the control group in their state of consumption, smoking or exercise. There are several cross-sectional and prospective studies suggesting a positive association between IGF-1 and atherosclerosis. ${ }^{23,24}$ Some studies have found that low IGF-1 index is a predictor of ischemic heart disease and mortality, due to its antiapoptotic, antioxidant and IGF-1 plateau stabilization actions. ${ }^{25}$
The results of two studies showed an association between low IGF1 and carotid risk and coronary artery disease, suggesting that the increase in GH/IGF-1 hormones is associated with the risk of lower atherosclerosis and consequently lower cardiovascular mortality. ${ }^{23-26}$

IGF-1 has an anti atherogenic effect related to the reduction of oxidative stress in the vasculature. ${ }^{26-29}$ Therefore, an imbalance in redox regulation is associated with aging, leading to elevated vascular oxidative stress, predisposing to atherogenesis.,30,31 The antioxidant effect of IGF-1 may represent an anti aging mechanism that contributes to the prevention of atherosclerosis. There is evidence that IGF-1 is able to preserve endothelial function. ${ }^{3}$ GH deficiency in the body impairs flow-mediated arterial dilatation and vasodilatationdependent endothelial NO, leading to increased cardiovascular morbidity and mortality. ${ }^{32}$

The GHD tests should be extended from hypothalamus-pituitary and cranial irradiation to include traumatic brain injury. The test may indicate GHD alone; however, idiopathic isolated GHD occurring again in the adult is not an entity. A low IGF-I is a reliable diagnostic indicator of GHD in the presence of hypopituitarism, but a normal IGF-I does not rule out GHD. The GH status should be reevaluated at the transition age for continued treatment to complete somatic development. The GH interaction with other axes can influence the requirements of thyroid, glucocorticoids and sexual hormone. The response should be assessed clinically by monitoring biochemistry, body composition and quality of life. There is no evidence that $\mathrm{GH}$ replacement increases the risk of recurrence of tumor or de novomalignancy. ${ }^{33,34}$

In addition, GHD may persist from childhood or be newly acquired. ${ }^{35,36}$ Confirmation by pacing tests is generally required unless there is a proven genetic/structural lesion persistent since childhood. ${ }^{37}$ GH therapy offers benefits in body composition, exercise capacity, skeletal integrity and quality of life measures and is more likely to benefit those patients who have more severe GHD. The risks of GH treatment are low. GH dosing regimens should be individualized. The final decision to treat adults with GHD requires a clinical assessment with timely judgment with a careful assessment of the benefits and risks specific to the individual. ${ }^{38}$

Recent work has shown the evaluation of the effect after four years of GH on glucose homeostasis and evaluation factors affecting $\mathrm{HbA1c}$ in adults with GHD. The mean standard deviation (HbA1c) was 5 to $13(0-65) \%$ and remained at the same level at four years. Age and BMI had a significant impact on $\triangle \mathrm{HbAlc}$. At four years, $85.0 \%$ of patients with $\mathrm{HbA} 1 \mathrm{c}<5-7.0 \%$ (normal levels) at the baseline and $55.0 \%$ of patients with $\mathrm{HbA1c} 5.7-6.5 \%$ (glucose tolerance altered) at the baseline remained in the same category of glycemic health. Nineteen patients improved from impaired glucose tolerance to normal HbAlc. Seven patients developed diabetes. These data demonstrate that 4-year GH replacement did not adversely affect glucose homeostasis in most adults with GHD. ${ }^{34}$

Another study, after using an evidence-based approach, has pointed to guidelines that address important clinical issues related to the assessment and management of adult hypopituitarism, including appropriate biochemical assessments, specific therapeutic decisions to reduce the risk of comorbidities due to hormone over- or subreplacement, and management of hypopituitarism during pregnancy, pituitary surgery and other types of surgeries. ${ }^{35}$ Thus, without regulation, GHD is associated with insulin efficiency and obesity. ${ }^{35}$ 
Lower levels of leptin, despite a higher percentage of body fat, suggest that obesity-associated leptin resistance is GH-dependent. Elevated levels of adiponectin uncorrelated with body fat percentage indicate that $\mathrm{GH}$ signaling is required for its typical obesity suppression. ${ }^{36}$

GH deficiency from onset to adulthood is a rare disease that most commonly results from pituitary tumors, and this may result in changes in body composition, carbohydrate and lipid metabolism, bone mineral density, cardiovascular risk profile and quality of life, which may contribute to greater morbidity and mortality. ${ }^{37,38}$ Since recombinant human GH (rhGH) became available in 1985, several studies have provided evidence of its beneficial effects despite the potential risk of developing adverse effects and much clinical experience has been accumulated. However, in adults, the precise therapeutic role of GH replacement therapy and the individual response to $\mathrm{GH}$ remains highly variable and is still a matter of debate..$^{38}$

\section{Conclusion}

The growth hormone GH and its IGF-1 axis are responsible not only for the growth of the human body, but also for the regularization of several factors that can lead to cardiovascular diseases. GH/IGF1 deficiency has been shown to accelerate atherosclerosis, causing endothelial dysfunction, reducing insulin, producing an increase in fat mass and also in systemic inflammatory activity. The drop in untreated GH can be a major risk factor, causing various reactions in the body and leading to heart disease.

\section{Acknowledgements}

None.

\section{Conflict of interest}

The author declares no conflict of interest.

\section{References}

1. World health organization. The top ten causes of death fact sheet. WHO; 2017

2. Pinho RA, Araújo MC, Ghisi GLM, et al. Coronary heart disease, physical exercise and oxidative stress. Arq Bras Cardiol. 2010;94(4):549-555.

3. Reed ML, Merriam GR, Kargi AY. Adult growth hormone deficiencybenefits, side effects, and risks of growth hormone replacement. Frontiers in Endocrinology. 2013;4:64.

4. Bostoganashvili N, Zerekidze $\mathrm{T}$, Janjgava $\mathrm{S}$, et al. The impact of 12-monthgrowth hormonereplacement therapy on lipid metabolism and adipose tissue distribution in Georgian patients with adult growth hormone deficiency. Georgian Med News. 2017;(273):36-41.

5. Hauffa BP, Touraine P, Urquhart-Kelly T, et al. Managing transition in patients treated with growth hormone. Front Endocrinol (Lausanne). 2017;8:346.

6. Xie X, Li Q, Zhang L, et al. Lipid accumulation product, visceral adiposity index and Chinese visceral adiposity index as markers of cardiometabolic risk in adult growth hormone deficiency patients: across-sectional study. Endocr Pract. 2018;24(1):33-39.

7. Caicedo A, Rosenfeld R. Challenges and future for the delivery ofgrowth hormonetherapy. Growth Horm IGF Res. 2018;38:39-43.

8. Di Somma C, Scarano E, Savastano S, et al. Cardiovascular alterations in adult GH deficiency. Best Pract Res Clin Endocrinol Metab. 2017;31(1):25-34.
9. Ascoli M, Segaloff DL. Adenohypophyseal hormones and their hypothalamic releasing factors. In Hardman JG, editors. The pharmacological basis of therapeutics. $9^{\text {th }} \mathrm{ed}$. New York: McGraw-Hill; 1996. p. 1009-1015.

10. Bernard R, Chan FY, Mcintyre HD. Growth hormone-binding protein in normal and pathologic gestation: correlations with maternal diabetes and fetal growth. J Clin Endocrinol Metab. 1997;82(6):1879-1884.

11. Barreto-Filho JA, Alcântara MR, Salvatori R, et al. Familial isolated growth hormone deficiency is associated with increased systolic blood pressure, central obesity, and syslipidemia. J Clin Endocrinol Metab. 2002;87(5):2018-2023.

12. Battin J. Current aspects of Turner syndrome. Arch Pediatrie. 1996;3(6):588-597.

13. Berne RM, Levy NM. Fisiologia. 2nd ed. Rio de Janeiro: Guanabara Koogan; 1990.

14. Markussis V, Beshyah SA, Fisher C, et al. Detection of premature atherosclerosis by high-resolution ultrasonography in symptom free hypopituitary adults. Lancet. 1992;340(8829):1188-1192.

15. Menezes OJL, Marques-Santos C, Barreto-Filho JA, et al. Lack of evidence of premature atherosclerosis in untreated severe isolated growth hormone $(\mathrm{GH})$ deficiency due to a GH-releasing hormone receptor mutation. J Clin Endocrin Metab. 2006;91(6):2093-2099.

16. Rosén T, Bengtsson BA. Premature mortality due to cardiovascular disease in hypopituitarism. Lancet. 1990;336(8710):285-288.

17. World health organization. Growth reference data for 5-19 years. Disponível em, WHO; 2013

18. Zannis VI, Cole FS, Jackson CL, et al. Distribution of apolipoprotein A-I, C-II, C-III, and E mRNA in fetal human tissues. Time-dependent induction of apolipoprotein E mRNA by cultures of human monocytemacrophages. Biochemistry. 1985;24(16):4450-4455.

19. Vijayakumar A, Novosyadlyy R, Wu Y, et al. Biological effects of growth hormone on carbohydrate and lipid metabolism. Growth Horm IGF Res. 2010;20(1):1-7.

20. Chaves VE, Júnior FM, Bertolini GL. The metabolic effects of growth hormone in adipose tissue. Endocrine. 2013;44(2):293-302.

21. Giovannini L, Tirabassi G, Muscogiuri G, et al. Impact of adult growth hormone deficiency on metabolic profile and cardiovascular risk. Endocr J. 2015;62(12):1037-1048.

22. De Boer H, Blok GJ, Voerman HJ, et al. Body composition in adult growth hormone deficient men, assessed by anthropometry and bioimpedance analysis. J Clin Endocrinol Metab. 1992;75(3):833-837.

23. Colao A, Di Somma C, Cuocolo A, et al. The severity of growth hormone deficiency correlates with the severity of cardiac impairment in 100 adult patients with hypopituitarism: an observational, case-control study. J Clin Endocrinol Metab. 2004;89(12):5908-6004.

24. Johansson JO, Fowelin J, Landin K, et al. Growth hormone deficient adults are insulin resistant. Metabolism. 1995;44(9):1126-1129.

25. Salomon F, Cuneo RC, Hesp R, et al. The effects of treatment with recombinant growth hormone on body composition and metabolism in adults with growth hormone deficiency. NEngl JMed. 1989;321(26):17971803.

26. Uzunova I, Kirilov G, Zacharieva S, et al. Individual risk factors of the metabolic syndrome in adult patients with growth hormone defciency - a cross-sectional case-control study. Exp Clin Endocrinol Diabetes. 2015;123(1):39-43. 
27. Després JP, Lemieux I, Bergeron J, et al. Abdominal obesity and the metabolic syndrome: contribution to global cardiometabolic risk. ArteriosclerThrombos Vasc Biol. 2008;28(6):1039-1049.

28. Kahn HS. The lipid accumulation product performs better than the body mass index for recognizing cardiovascular risk: a population-based comparison. BMC Cardiovasc Disord. 2005;5:26.

29. Qing L, Wei R, Chan L, et al. Sensitivity of various body indices and visceral adiposity index in predicting metabolic syndrome among Chinese patients with adult growth hormone deficiency. J Endocrinol Invest. 2017;40(6):653-661.

30. Ken KY. Consensus guidelines for the diagnosis and treatment of adults with GH deficiency II: a statement of the GH Research Society in association with the European society for pediatric endocrinology, Lawson Wilkins society, European society of endocrinology, Japan endocrine society, and endocrine society of Australia. Eur J Endocrinol. 2007;157(6):695-700.

31. Molitch ME, Clemmons DR, Malozowski S, et al. Evaluation and treatment of adult growth hormonedeficiency: an Endocrine Society clinical practice guideline. J Clin Endocrinol Metab. 2006;91(5):16211634.
32. Weber MM, Biller BMK, Pedersen BT, et al. The effect of growth hormone $(\mathrm{GH})$ replacement on blood glucose homeostasis in adult nondiabetic patients with GH deficiency: real-life data from the NordiNet_ International outcome study. Clin Endocrinol. 2017;86(2):192-198.

33. Fleseriu M, Hashim IA, Karavitaki N, et al. Hormonal replacement in hypopituitarism in adults: an Endocrine Society clinical practice guideline. J Clin Endocrinol Metab. 2016;101(11):3888-3921.

34. Guevara-Aguirre J, Rosenbloom AL, Balasubramanian P, et al. GH receptor deficiency in Ecuadorian adults isassociated with obesity and enhanced insulinsensitivity. J Clin Endocrinol Metab. 2015;100(7):2589 2596.

35. Castilla-Cortazar I, De Ita JR, Aguirre GA, et al. Primary growth hormone insensitivity and psychomotor delay. Clin Case Rep. 2018;18;6(2):426431.

36. Ramos-Leví AM, Marazuela M. Treatment of adult growth hormone deficiency with human recombinant growth hormone: an update on current evidence and critical review of advantages and pitfalls. Endocrine. 2018;60(2):203-218. 